\title{
Destructive Effect of Zinc on TEX - A DFT Treatment
}

\section{Lemi Türker}

Department of Chemistry, Middle East Technical University, Üniversiteler, Eskişehir Yolu No: 1, 06800 Çankaya/Ankara, Turkey; e-mail: lturker@gmail.com; lturker@metu.edu.tr

\begin{abstract}
Various metal components like $\mathrm{Al}, \mathrm{B}, \mathrm{Zr}$ etc., as energetic particles are employed in thermobaric explosives. In composite systems compatibility of ingredients with each other is an important point to be considered. In the present study, effect of zinc on TEX, which is a caged explosive of nitramine type is investigated within the constraints of density functional theory at the levels of B3LYP/6-31+G(d), $\omega \mathrm{B} 97 \mathrm{X}-\mathrm{D} / 6-31 \mathrm{G}(\mathrm{d})$ and $\omega \mathrm{B} 97 \mathrm{X}-$ $\mathrm{D} / 6-31+\mathrm{G}(\mathrm{d})$. Various quantum chemical properties have been calculated for the TEX $+\mathrm{Zn}$ composite and compared with TEX. The zinc atom interacts with TEX molecule via destructive reduction of the explosive. The B3LYP/6-31+G(d) level of calculation predicts cleavage of one of the etheric bond of the cage as well as $\mathrm{N}-\mathrm{NO}_{2}$ bond. Whereas, $\omega B 97 X-D / 6-31 G(d)$ and $\omega B 97 X-D / 6-31+G(d)$ level of treatments show cleavage of only one of the $\mathrm{N}-\mathrm{NO}_{2}$ bonds. In all the cases the zinc atom acquires some positive charge development.
\end{abstract}

\section{Introduction}

4,10-Dinitro-2,6,8,12-tetraoxa-4,10-diazawurtzitane, known as TEX (see Figure 1) stands for one of the nitramine type energetic materials which has attracted attention in recent years as insensitive and thermally stable energetic materials [1]. Moreover, its cage structure with etheric (acetal) bonds as well as two nitramine linkages makes it a candidate for various scientific investigations. The first synthesis of TEX was managed by Boyer and coworkers in two-step synthesis [2]. They started with form amide and glyoxal to obtain TEX. The synthesis involved a piperazine derivative as an intermediary Received: September 2, 2019; Accepted: November 2, 2019

Keywords and phrases: TEX, zinc, density functional, destruction, reduction.

Copyright $\odot 2020$ Lemi Türker. This is an open access article distributed under the Creative Commons Attribution License, which permits unrestricted use, distribution, and reproduction in any medium, provided the original work is properly cited. 
product [2]. TEX has two nitramine bonds and additionally contains two embedded fivemembered cyclic dietheric structures which can also be considered as acetal, thereby resembling to 1,3-dioxalane. An improved and scalable synthesis of TEX has been reported [3].

TEX possesses some ballistically desirable properties such as high density (1.99 $\left.\mathrm{g} / \mathrm{cm}^{3}\right)$ and excellent thermal stability (m.p $\left.>240^{\circ} \mathrm{C}\right)$, high detonation velocity $(8665 \mathrm{~m} / \mathrm{s}$ ) and pressure (370 kbar) [1, 2, 4-8].

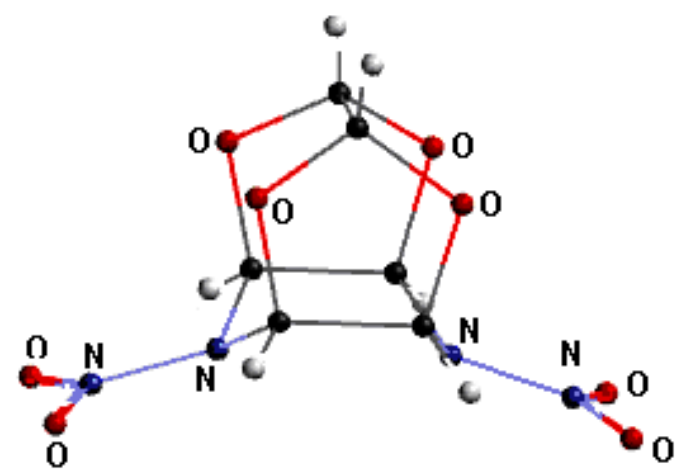

Figure 1. Structure of TEX.

Two 1,3-dioxalane structures embedded in TEX remind some well known reactions of ethers and acetals (cyclic or acyclic). One of those is the well known acid catalyzed ring opening reactions of cyclic ethers [9-11]. One can consider the embedded 1,3dioxalane structures in TEX as full acetal of glyoxal. It is known that acetal formation and destruction are acid catalyzed reactions [9-11]. Therefore, the protonation of TEX was investigated within the limitations of density functional theory [12].

The presence of nitro groups as a part of nitramine moiety in TEX structure recalls reduction reactions of organic chemistry. Zinc in different media is often used to reduce nitro groups on aromatic structures to produce variety of compounds [9-10, 13]. However, the reduction of aliphatic nitro compounds to amines is of little importance because the amino group is easily introduced in a number of different ways [13] contrary to the case in aromatic series.

Reduction of aliphatic nitramines by using various agents appeared in the literature [14-18]. On the other hand, various metal powders are incorporated in formulations of explosive materials [19-22]. 
In the present study, interaction of TEX with $\mathrm{Zn}$ has been investigated. Note that, such kind of investigation is absent to the best of knowledge of the author.

\section{Method of Calculations}

Geometry optimizations of all the presently considered systems (TEX and TEX+Zn) leading to energy minima were initially achieved by using MM2 method followed by semi-empirical PM3 self-consistent fields molecular orbital (SCF MO) method [23, 24] at the restricted level $[25,26]$. Subsequent optimizations were achieved at Hartree-Fock level using various basis sets hierarchically. Then, geometry optimizations were managed within the framework of density functional theory (DFT) using B3LYP [27, 28] and $\omega B$ 97X-D $[29,30]$ functionals at the levels of $6-31 G(d)$ and $6-31+G(d, p)$. The exchange term of B3LYP consists of hybrid Hartree-Fock and local spin density (LSD) exchange functions with Becke's gradient correlation to LSD exchange [31, 32]. Note that the correlation term of B3LYP consists of the Vosko, Wilk, Nusair (VWN3) local correlation functional [32] and Lee, Yang, Parr (LYP) correlation correction functional [33]. Presently, the vibrational analyses have been also done at the same level of calculations which had been performed for the optimizations. The total electronic energies (E) are corrected for the zero point vibrational energy (ZPE) to yield $E_{c}$ values. The normal mode analysis for each structure yielded no imaginary frequencies for the $3 N-6$ vibrational degrees of freedom, where $N$ is the number of atoms in the system. This indicates that the structure of each molecule corresponds to at least a local minimum on the potential energy surface. All these calculations were done by using the Spartan 06 package program [34].

\section{Results and Discussion}

Zinc atom has $1 s^{2} 2 s^{2} 2 p^{6} 3 s^{2} 3 p^{6} 3 d^{10} 4 s^{2}$ electronic configuration in its ground state. It is a closed shell system and donating its $4 \mathrm{~s}$ electrons it may reduce certain organic functional groups. The ionization potential of zinc is $9.36 \mathrm{eV}$ and $17.89 \mathrm{eV}$, respectively for the first and second oxidation states [35].

Figure 2 shows the optimized structure of TEX $+\mathrm{Zn}$ composite according to various level of calculations. Figure indicates that the optimization is some what depends on the calculation level. For instance, B3LYP/6-31+G(d) optimized system underwent bond cleavages of one of the cage bonds $\left(\mathrm{C}-\mathrm{O}\right.$ bond) as well as one of the nitramine $\left(\mathrm{N}^{-\mathrm{NO}_{2}}\right)$ 
bonds. On the other hand, $\omega \mathrm{B} 97 \mathrm{X}-\mathrm{D} / 6-31 \mathrm{G}(\mathrm{d})$ and $\omega \mathrm{B} 97 \mathrm{X}-\mathrm{D} / 6-31+\mathrm{G}(\mathrm{d})$ level of calculations keep the cage intact but only one of the nitramine bonds was broken.

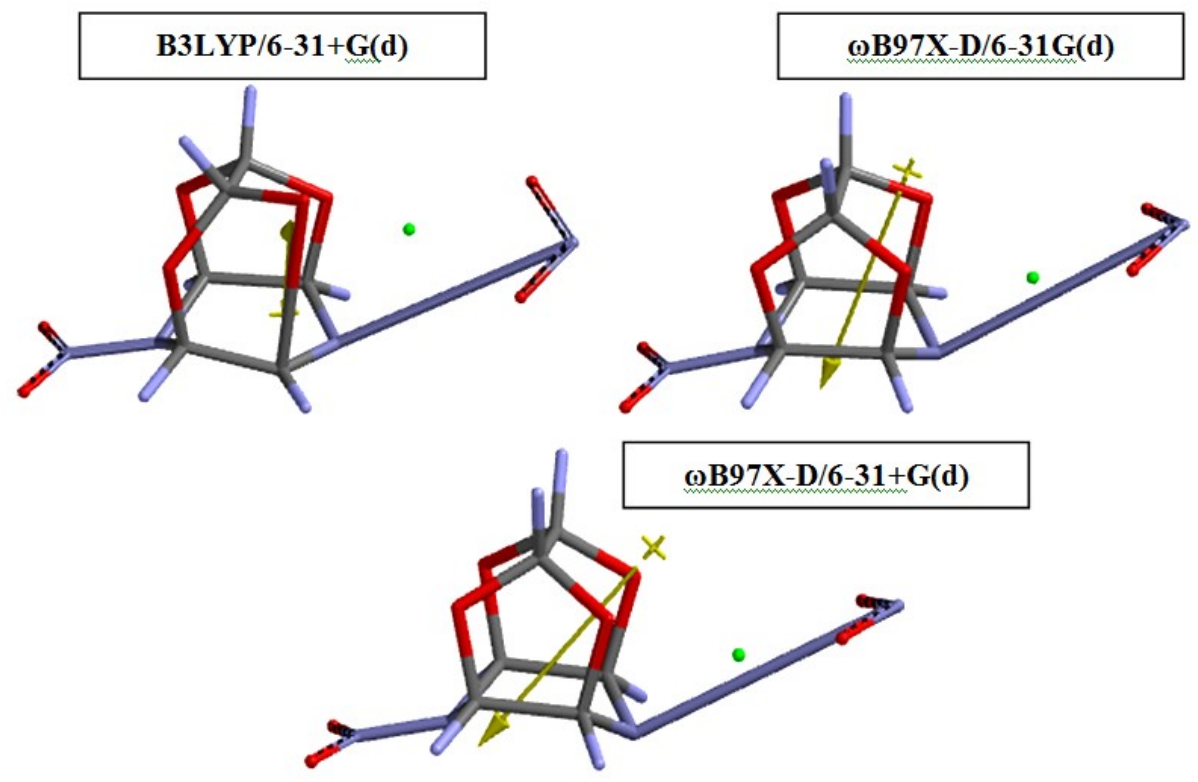

Figure 2. Optimized structure of the composite.

Figure 3 shows the bond lengths/distances of TEX and the composite system. In the case of B3LYP/6-31+G(d) level of optimization one of the etheric C-O bonds seems to be highly elongated (2.91 $\AA$ ). Since etheric $\mathrm{C}-\mathrm{O}$ bonds characteristically are in the range of 1.40-1.43 $\AA$ (in tetrahydrofuran $1.428 \AA$ ) [36], the bond in the composite, at this level of calculations, stands for a broken bond. The calculations based on $\omega$ B97X-D functional definitely keep the cage intact but one of the nitramine bonds as seen in Figure 3 is cleaved.

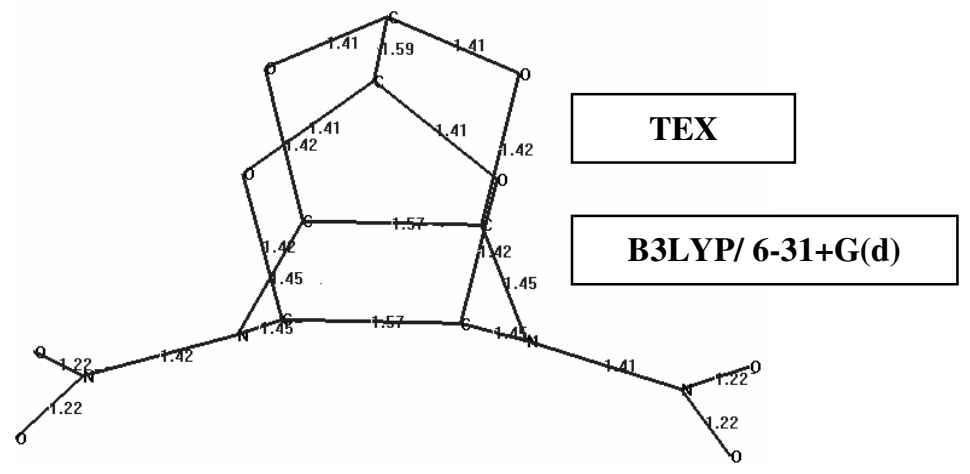



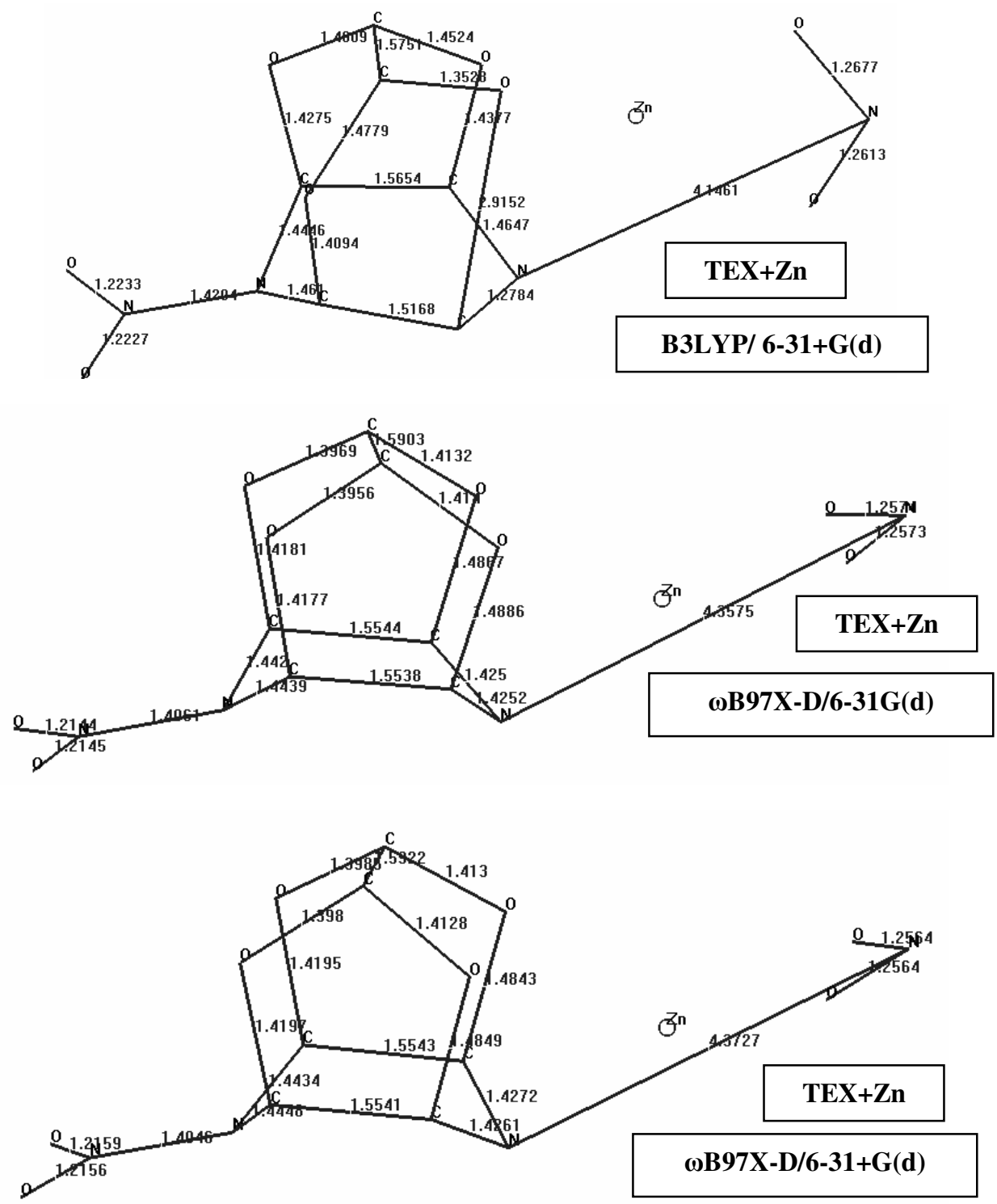

Figure 3. Bond lengths /distance $(\AA)$ of TEX and the composite.

Figure 4 displays the IR spectra of the composite as well as TEX alone. In all the cases, the sharp peak about $1660 \mathrm{~cm}^{-1}$ stands for asymmetric N-O stretching. The broad peaks about $1300-1400 \mathrm{~cm}^{-1}$ are wagging of hydrogens and symmetrical N-O stretching. 

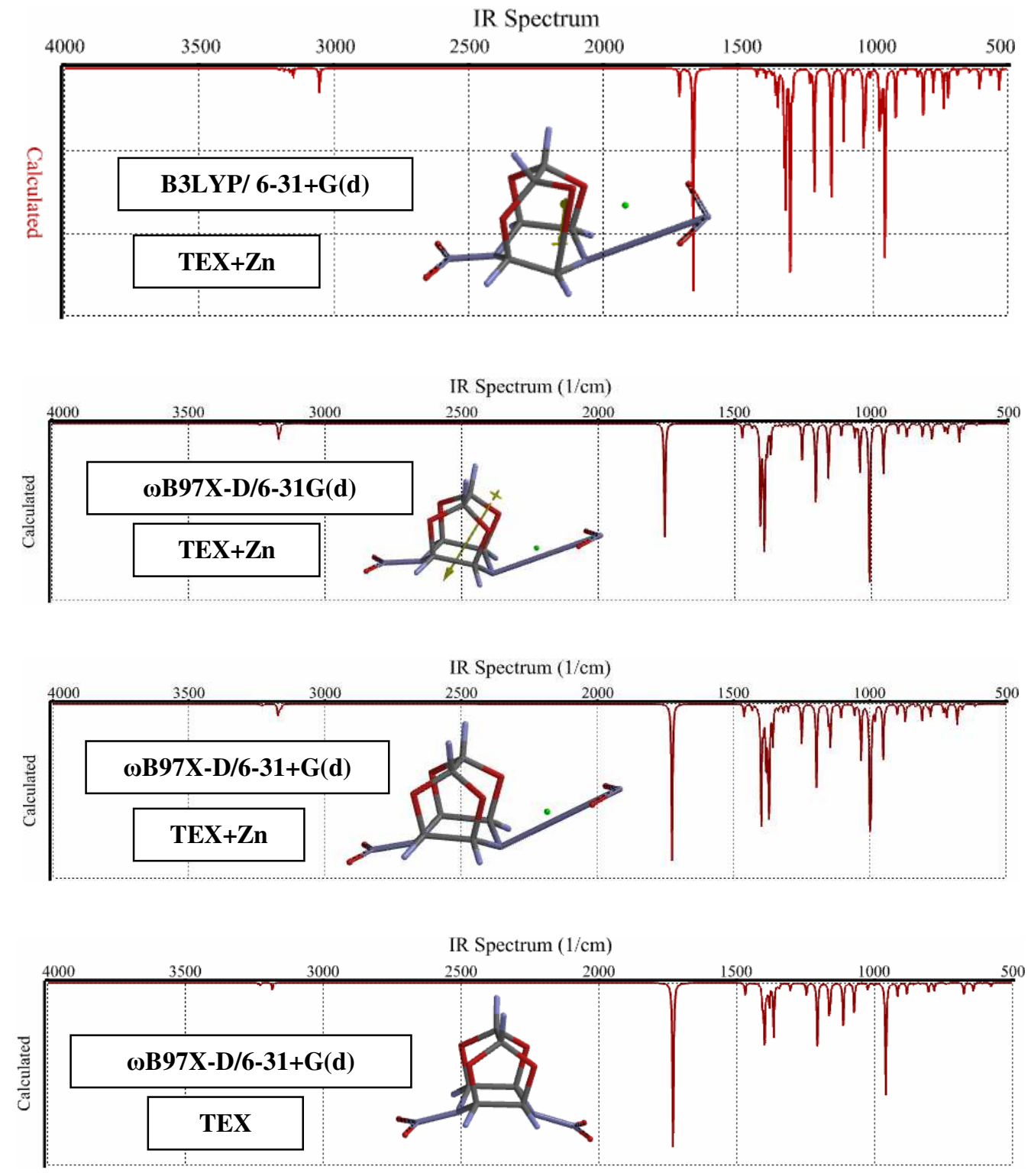

Figure 4. IR spectra of TEX+Zn and TEX.

Figure 5 shows the ESP and natural charges on the atoms of TEX. Note that the ESP charges are obtained by the program based on a numerical method which generates charges that reproduce the electrostatic potential field from the entire wavefunction [34]. 


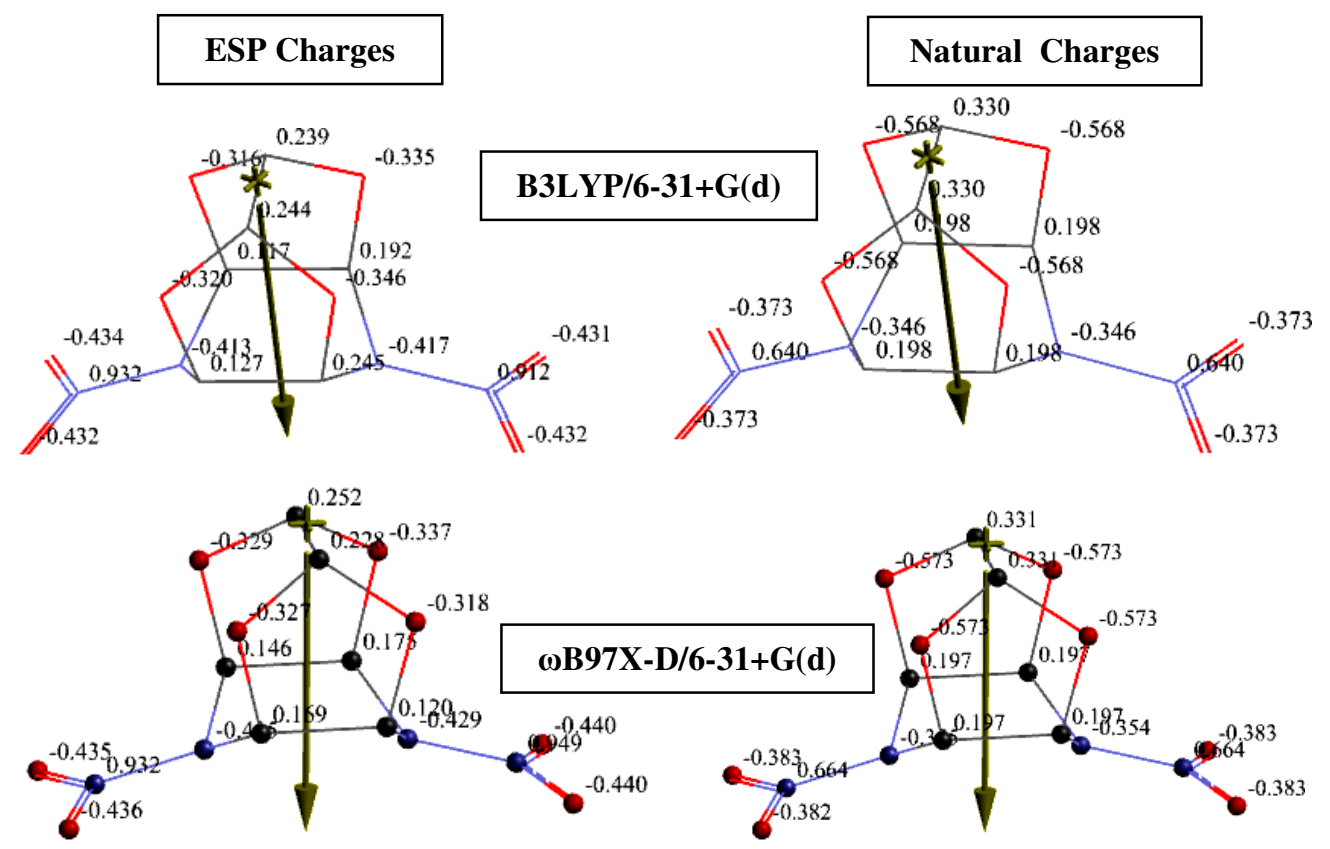

Figure 5. ESP and natural charges on the atoms of TEX (hydrogens omitted).

As seen in the figure, the natural charge distribution in TEX is more or less symmetrical (by the both types of calculations) but it is not the case for ESP charges. The nitro groups are not identical in terms of ESP charges of nitro nitrogens (0.932 and 0.949 , respectively) and nitro oxygens $(-0.435,-0.436$ and $-0.440,0.440$, respectively). The amine nitrogens of the nitramine bonds are negatively charged in all the cases. Figure 6 shows the electrostatic potential map of TEX (WB97X-D/6-31+G(d)). In the figure the blue and red regions stand for positive and negative potential regions, respectively. Thus, the base ring of TEX possesses highly positive potential.
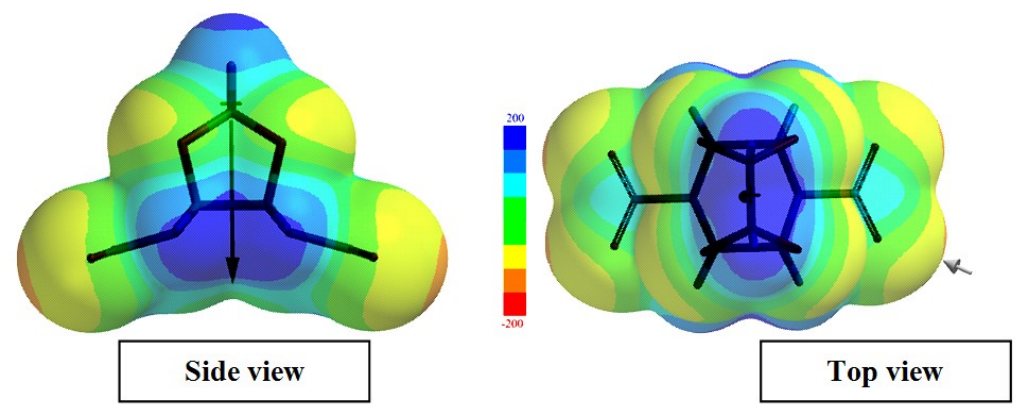

Figure 6. Electrostatic potential map of TEX (WB97X-D/6-31+G(d)). 
Figures 7 and 8 show the ESP and natural charges on the atoms of the composite system, respectively by different types of calculations.

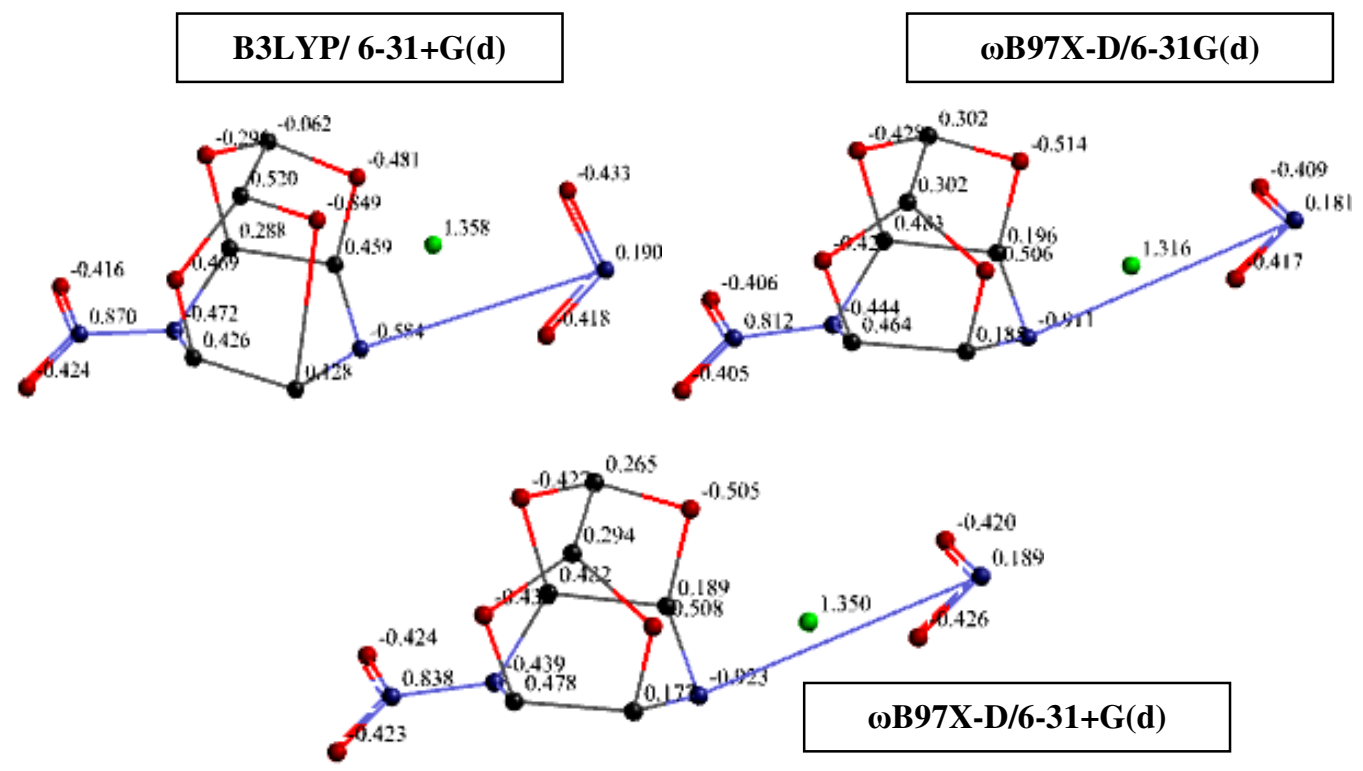

Figure 7. ESP charges on the atoms of the composite (hydrogens omitted).

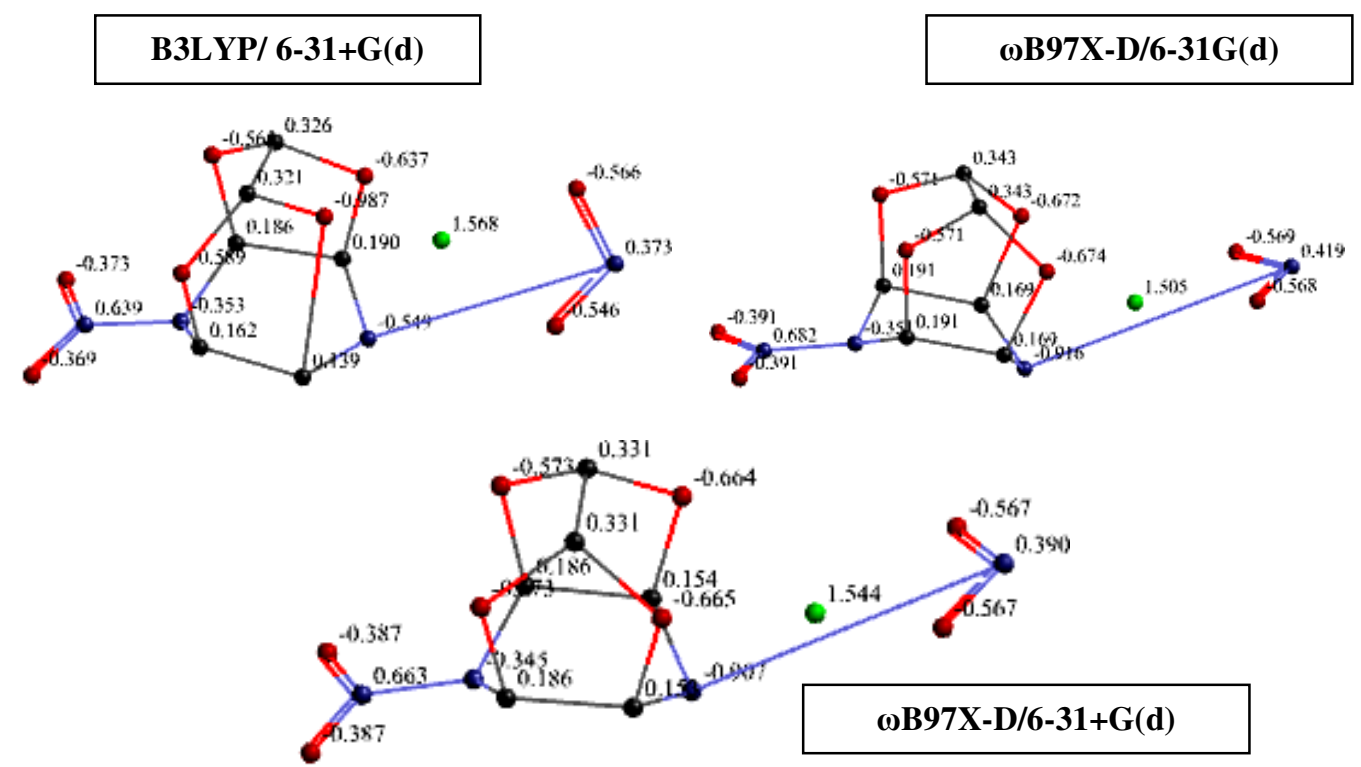

Figure 8. Natural charges on the atoms of the composite (hydrogens omitted). 
After the reduction by zinc, nitrogen of the broken nitramine bond remaining in the cage structure has more negative (increased in absolute value) ESP and natural charges as compared to the nitramine bond remained intact (on the other side of the cage). The zinc atom in all the cases possesses some positive charge. The departing $\mathrm{NO}_{2}$ moiety in all the cases has some negative over all charge. Some energies of the composite are tabulated in Table 1 and give some idea how the energies vary according to the functional and the basis set employed.

Table 1. Some energies of the composite.

\begin{tabular}{|l|c|c|c|}
\hline \multicolumn{1}{|c|}{ Level of calculation } & $\mathbf{E}$ & $\mathbf{Z P E}$ & $\mathbf{E}_{\mathbf{c}}$ \\
\hline B3LYP/6-31+G(d) & -7435480.62 & 417.56 & -7435063.06 \\
\hline$\omega B 97 X-D / 6-31 G(d)$ & -7434544.54 & 433.84 & -7434110.7 \\
\hline$\omega B 97 X-D / 6-31+G(d)$ & -7434646.49 & 431.97 & -7434214.52 \\
\hline
\end{tabular}

Energies in $\mathrm{kJ} / \mathrm{mol}$.

Some molecular orbital energy levels of TEX and TEX+Zn composite are displayed by Figure 9. Comparison of the respective parts of the figure for TEX and the composite at the level of B3LYP/6-31+G(d) indicates that the composite has higher HOMO but lower LUMO energy levels (see also Table 2). On the other hand, the calculations based on $\omega \mathrm{B} 97 \mathrm{X}-\mathrm{D}$ functional estimate lower HOMO but higher LUMO energy values as compared to B3LYP functional. Table 2 also includes the interfrontier molecular orbital gap $(\Delta \varepsilon)$ of the composite which has the order of B3LYP/6-31+G(d) $<\omega B$ 97X-D/6$31+\mathrm{G}(\mathrm{d})<\omega \mathrm{B} 97 \mathrm{X}-\mathrm{D} / 6-31 \mathrm{G}(\mathrm{d})$.

Table 2. The frontier molecular orbital energies and interfrontier molecular orbital gap $(\Delta \varepsilon)$ of the composite.

\begin{tabular}{|l|c|c|c|}
\hline Level of calculation & HOMO & LUMO & $\Delta \varepsilon$ \\
\hline B3LYP/6-31+G(d) & -753.51 & -281.90 & 471.61 \\
\hline$\omega B 97 X-D / 6-31 G(d)$ & -903.87 & -9.57 & 894.30 \\
\hline$\omega B 97 X-D / 6-31+G(d)$ & -927.53 & -43.16 & 884.37 \\
\hline
\end{tabular}

Energies in $\mathrm{kJ} / \mathrm{mol}$. The respective energies of TEX are -802.18 and -269.68 $\mathrm{kJ} / \mathrm{mol}$, respectively (B3LYP/6-31+G(d) level). 

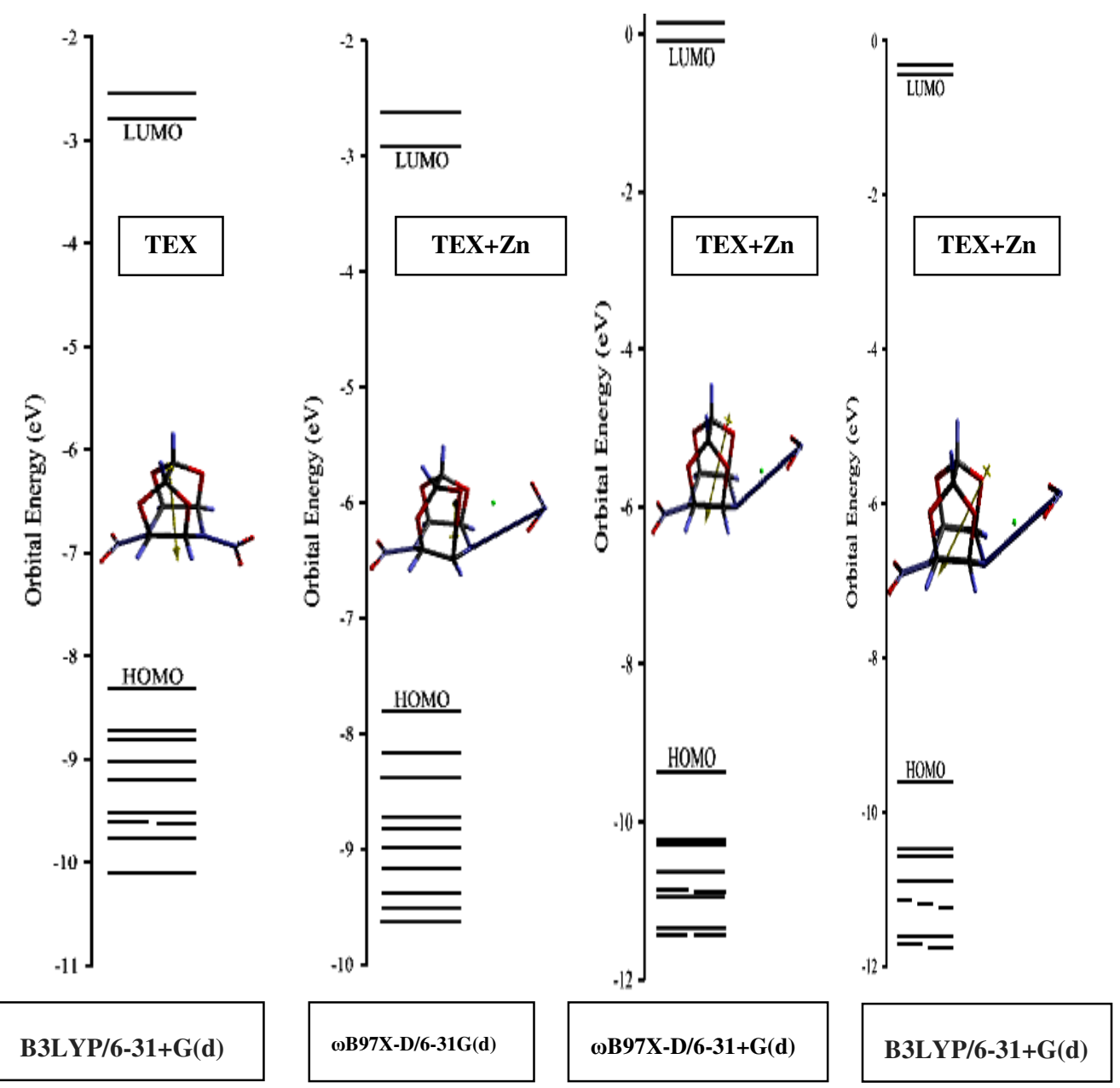

Figure 9. Some molecular orbital energy levels of TEX and TEX+Zn composite.

The HOMO and LUMO patterns of the composite at different levels of calculations are shown in Figure 10. The nitro group of the unbroken nitramine bond does not participate into the HOMO in the case of $\omega \mathrm{B} 97 \mathrm{X}-\mathrm{D}$ functional irrespective of the basis set used. Its contribution is very small at the B3LYP/6-31+G(d) level. As for the LUMO orbital, the only contribution comes from the departing $\mathrm{NO}_{2}$ moiety if $\omega \mathrm{B} 97 \mathrm{X}-\mathrm{D}$ functional is employed. At the B3LYP/6-31+G(d) level most of the cage atoms also contribute in to the LUMO. 

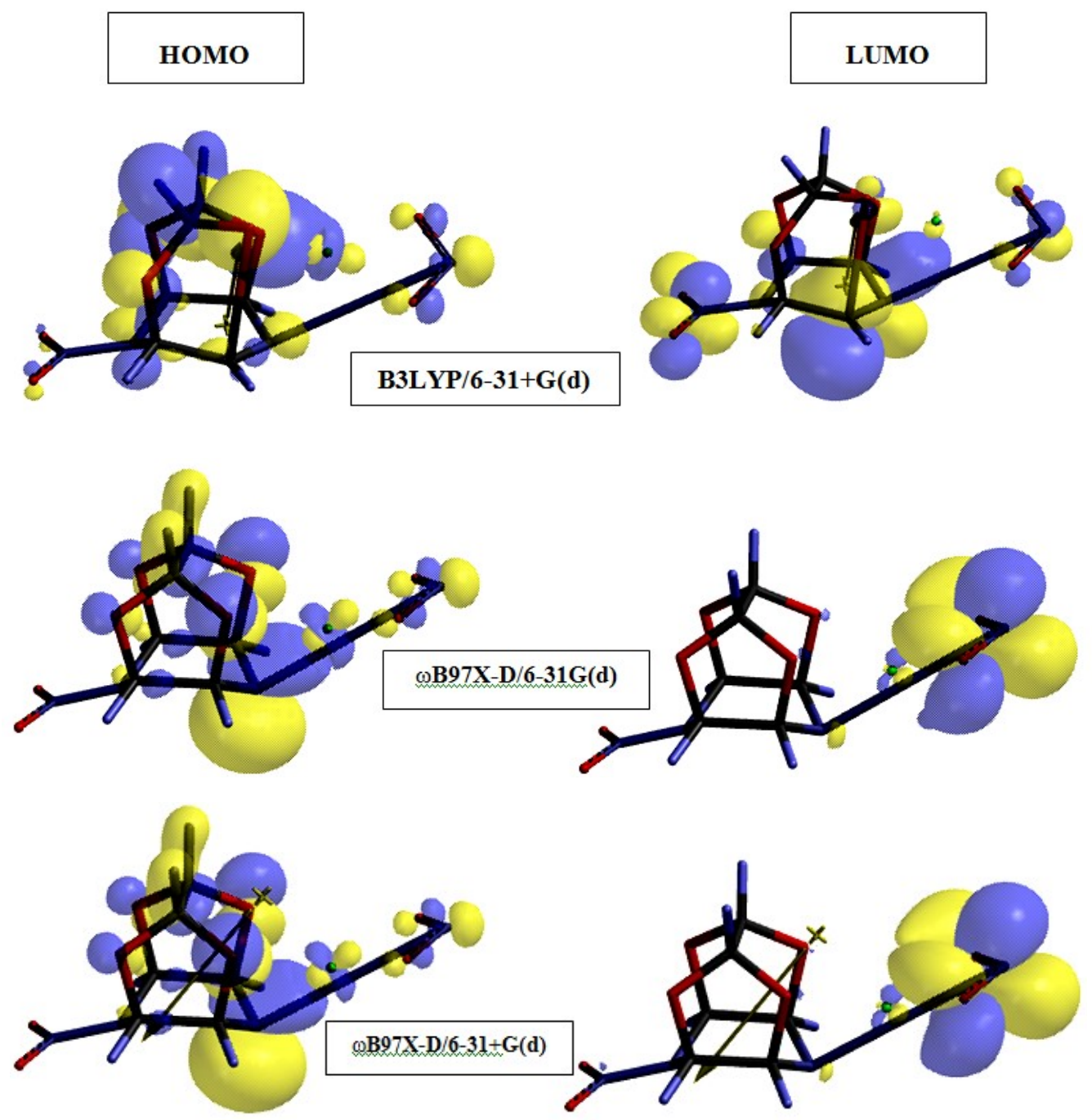

Figure 10. The HOMO and LUMO patterns of the composite.

Figure 11 displays the electrostatic potential maps of the composite. The positive and negative potential regions are represented in blue and red shades, respectively. Generally the base and some part of the attic region of the cage are positive (compare with TEX in Figure 6). The $\mathrm{NO}_{2}$ moiety of the broken nitramine bond possesses some negative potential. In the case of B3LYP/6-31+G(d) level of calculations oxygen atom of the raptured etheric bond has negative potential. 


\section{B3LYP/6-31+G(d)}
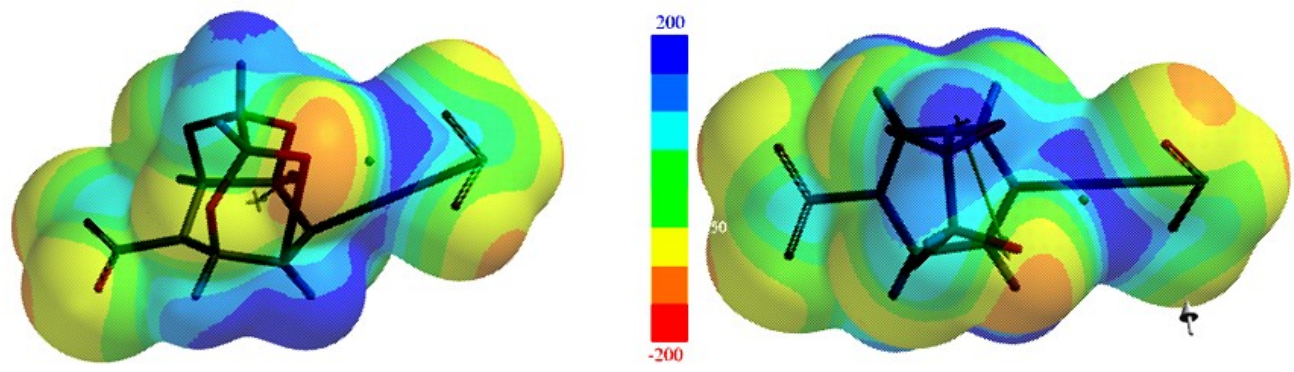

\section{WB97X-D/6-31G(d)}
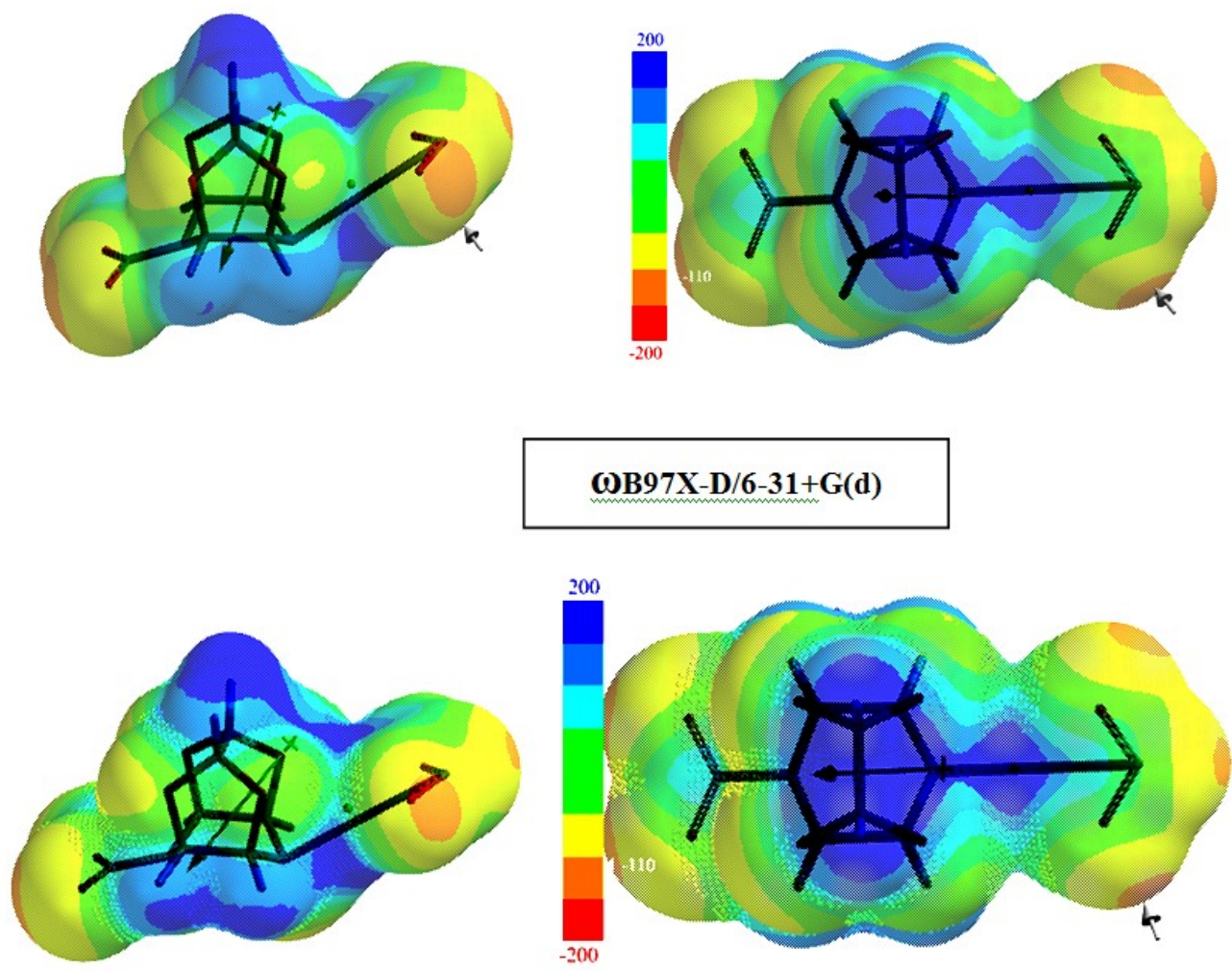

Figure 11. Electrostatic potential maps of the composite (two different views). 


\section{Conclusion}

The present study within the constraints of the density functional theory at the applied level of calculations has investigated the action of zinc on TEX structure. Although some of the results are depended on the functional and basis set employed, the common point is that zinc is not compatible with TEX molecule and one of the nitramine bonds in the presence of $\mathrm{Zn}$ undergoes cleavage expelling a $\mathrm{NO}_{2}$ group, irrespective of the DFT functionals and basis sets employed. The decomposition process is a reduction, the zinc atom supplies some electron population to the cage and the $\mathrm{NO}_{2}$ group, gaining itself some positive charge. In the light of the results, it seems that zinc is not a suitable material to be used for the purpose of enhancing heat characteristics of TEX molecule.

\section{References}

[1] A. K. Sikder and N. Sikder, A review of advanced high performance, insensitive and thermally stable energetic materials emerging for military and space applications, $J$. Hazardous Materials A 112 (2004), 1-15. https://doi.org/10.1016/j.jhazmat.2004.04.003

[2] V. T. Ramakrishnan, M. Vedachalam and J. H. Boyer, 4,10-Dinitro-2,6,8,12-tetraoxa4,10-diazatetracyclo(5,5,0,0,3,11)dodecane, Heterocycles 31 (1990), 479-480. https://doi.org/10.3987/COM-89-5192

[3] M. B. Deshmukh, A. U. Borse, P. P. Mahulikar and D. S. Dalal, An improved and scalable synthesis of insensitive high explosive 4,10-dinitro-2,6,8,12-tetraoxa-4,10diazaisowurtzitane (TEX), Org. Process Res. Dev. 20(7) (2016), 1363-1369. https://doi.org/10.1021/acs.oprd.6b00066

[4] J. Legard, The Preparatory Manual of Explosives, 3rd ed., 2007.

[5] G. A. Olah and D. R. Squire, Chemistry of Energetic Materials, Boston: Academic Press, 1991.

[6] J. P. Agrawal and R. D. Hodgson, Organic Chemistry of Explosives, Sussex: Wiley, 2007. https://doi.org/10.1002/9780470059364

[7] T. M. Klapötke, Chemistry of High Energy Materials, Berlin: De Gruyter, 2011. https://doi.org/10.1515/9783110227840

[8] K. Karaghiosoff, T. M. Klapötke, A. Michailovski and G. Holl, 4,10-Dinitro-2,6,8,12tetraoxa-4,10-diazawurtzitane (TEX): a nitramine with an exceptionally high density, Acta Cryst. C 58 (2002), 580-581. https://doi.org/10.1107/S0108270102014774 
[9] J. March, Advanced Organic Chemistry, London: McGraw-Hill Int., 1977.

[10] R. C. Fuson, Reactions of Organic Compounds, New York: Wiley, 1962.

[11] A. Streitwieser, Jr. and C. H. Heatcock, Introduction to Organic Chemistry, New York: Macmillan Pub., 1976.

[12] L. Türker, Contemplation on protonation of TEX, Central European Journal of Energetic Materials, CEJEM 11 (2014), 3-15.

[13] R. O. C. Norman, Principles of Organic Synthesis, London: Methuen, 1970.

[14] P. de Armas, C. G. Francisco, R. Hernández and E. Suárez, Reduction of aliphatic nitramines. Approach to the synthesis of nitrosamines and amines, Tetrahedron Letters 27 (1986), 3195-3198. https://doi.org/10.1016/S0040-4039(00)84752-8

[15] H. Nivinskas, J. Sarlauskas, Z. Anusevicius, H. S. Toogood, N. S. Scrutton and N. Cenas, Reduction of aliphatic nitroesters and $N$-nitramines by Enterobacter cloacae PB2 pentaerythritol tetranitrate reductase: Quantitative structure-activity relationships, FEBS Journal 275 (2008), 6192-6203. https://doi.org/10.1111/j.1742-4658.2008.06744.x

[16] P. Kumar and K. L. Rai, Reduction of aromatic nitro compounds to amines using zinc and aqueous chelating ethers: Mild and efficient method for zinc activation, Chemical Papers 66(8) (2012), 772-778. https://doi.org/10.2478/s11696-012-0195-6

[17] M. J. Haire, Improved reduction of nitrimines to nitramines using sodium borohydride and acetic acid, J. Org. Chem. 42(21) (1977), 3446-3447. https://doi.org/10.1021/jo00441a031

[18] L. F. Cannizzo and L. R. Huntsman, Destruction of nitramines employing aqueous dispersions of metal powders, US005523517A, 1996.

[19] W. A. Trzciński, S. Cudziło, Z. Chyłek and L. Szymańczyk, Detonation properties and thermal behavior of FOX-7-Based explosives, Journal of Energetic Materials 31(1) (2013), 72-85. https://doi.org/10.1080/07370652.2011.611579

[20] L. Türker, Thermobaric and enhanced blast explosives (TBX and EBX), Defence Technology 12(6) (2016), 423-445. https://doi.org/10.1016/j.dt.2016.09.002

[21] N. H. Yen and L. Y. Wang, Reactive metals in explosives, Propellants, Explosives, Pyrotechnics 37(2) (2012), 143-155. https://doi.org/10.1002/prep.200900050

[22] Y. Choi, S. Jeong, H. Ryu, K. Lee, B. H. Bae and K. Nam, Ecological risk characterization in a military heavy metals- and explosives-contaminated site, Human and Ecological Risk Assessment: An International Journal 17(4) (2011), 856-872. https://doi.org/10.1080/10807039.2011.588151 
[23] J. J. P. Stewart, Optimization of parameters for semiempirical methods I. Method, J. Comput. Chem. 10 (1989), 209-220. https://doi.org/10.1002/jcc.540100208

[24] J. J. P. Stewart, Optimization of parameters for semiempirical methods II. Applications, $J$. Comput. Chem. 10 (1989), 221-264. https://doi.org/10.1002/jcc.540100209

[25] A. R. Leach, Molecular Modeling, Essex: Longman, 1997.

[26] P. Fletcher, Practical Methods of Optimization, New York: Wiley, 1990.

[27] W. Kohn and L. J. Sham, Self-consistent equations including exchange and correlation effects, J. Phys. Rev. 140 (1965), 1133-1138. https://doi.org/10.1103/PhysRev.140.A1133

[28] R. G. Parr and W. Yang, Density Functional Theory of Atoms and Molecules, London: Oxford University Press, 1989.

[29] Y. Minenkov, A. Singstad, G. Occhipinti and V. R. Jensen, The accuracy of DFToptimized geometries of functional transition metal compounds: a validation study of catalysts for olefin metathesis and other reactions in the homogeneous phase, Dalton Trans. 41(18) (2012), 5526-5541. https://doi.org/10.1039/c2dt12232d

[30] S. Kozuch and J. M. L. Martin, Halogen bonds: Benchmarks and theoretical analysis, J. Chem. Theory Comput. 9 (2013), 1918-1931. https://doi.org/10.1021/ct301064t

[31] A. D. Becke, Density-functional exchange-energy approximation with correct asymptotic behavior, Phys. Rev. A 38 (1988), 3098-3100.

https://doi.org/10.1103/PhysRevA.38.3098

[32] S. H. Vosko, L. Wilk and M. Nusair, Accurate spin-dependent electron liquid correlation energies for local spin density calculations: a critical analysis, Can. J. Phys. 58 (1980), 1200-1211. https://doi.org/10.1139/p80-159

[33] C. Lee, W. Yang and R. G. Parr, Development of the Colle-Salvetti correlation-energy formula into a functional of the electron density, Phys. Rev. B 37 (1988), 785-789. https://doi.org/10.1103/PhysRevB.37.785

[34] SPARTAN 06, Wavefunction Inc., Irvine CA, USA, 2006.

[35] P. J. Durant and B. Durant, Introduction to Advanced Inorganic Chemistry, London: Longman, 1972.

[36] L. V. Vilkov, V. S. Mastryukov and N. I. Sadova, Determination of the Geometrical Structure of Free Molecules, Moscow: Mir Pub, 1983. 